at the ends. A number of such sequences are possible according to the factors chosen as being most important. A more usual method of handling the data is by "classification' when like samples are grouped together. In both cases a personal decision as to the relative importance of the different factors involved determines the rosults; it should be remembered that what seems unimportant at the time of sampling in ecological work may be of great interest in later years. Although both principal component analysis and canonical correlation analysis are being tried, some other analysis, more easily interpreted, is required. Dale is hopeful that, by introducing some form of 'weighting', he will be able to produce a satisfactory classification method.

In the final general discussion, Jeffers said that suitable statistical techniques were becoming so advanced that the service of one professional statistician would be required to about six research workers, if full value was to be obtained from an oxpcriment. With the present shortage of statisticians that ideal seems remote, but members of the symposium welcomed Prof. Bunting's announcement that, beginning in October 1966, there would probably be a one-year M.Sc. course in biometry at the University of Reading. Nevertheless, research workers will still have to formulate a hypothesis, be able to discuss the layout of the experiment with a statistician, supervise the day-to-day management and obtain appropriato data. Finally, even if the analysis is obtained for him by the statistician, with the use of an olectronic computer, he must be able to discuss the interpretation of the results and translate them into biological terms. A working knowledge of the 'language' of statistics and of the underlying principles would seem to be increasingly necessary for all those responsible for ficld and glasshouse experiments and for those interested in the application of their results. It is hoped that another symposium will be arranged to continue the education of the non-statis. tician who uses statistical tools.

Members of the three organizations responsible for the symposium are greatly indebted to $\mathrm{Mr}$. J. H. Walker, of East Malling Research Station, for arranging this symposium and to the various speakers for presenting their specialized subjects to an audience of horticulturists and biologists, many of whom had had no formal training in statistical methods.

\section{E. Marston}

\title{
EUROPEAN JOURNAL OF CANCER
}

$\mathrm{T}$ HERE is, and has been since 1936 when the International Union Against Cancer was founded, extonsive international collaboration and exchange in the field of cancer research. This co-operation has been stimulated in recent years by the idea of an international institution of cancer research located in Europe and also by the efforts of the World Health Organization. At the European regional level such groups as the European Committee for Cancer Chemotherapy and the European Committee for Human Tumour Investigation are also playing their part in enoouraging inter-European collaboration between clinicians and scientists engaged in the study of cancerous diseases. It is logical that these Europenn groups and their associated workers should now have a journal which will provide a forum for the exchange of ideas and information. This journal is the European Journal of Cancer which made its first appearance in June of last year *.

The editorial advisory board of the new journal consists of workers of repute in the cancer field drawn from nine European countries, and the policy of the board will be to publish original work in the field of experimental and clinical cancer research, papers giving the results of planned clinical studies and also genoral reviews on subjects of particular rolovance to these researches and studies.

The first issue contains eight papers from laboratories and centres in Bolgium, France, Holland and Italy, so justifying the adjective European in the journal's title. There are two papers from the Radiological Institute of the Netherlands. Ono by L. M. van Putten presents the results of studies on the effects of different storage techniques on mouse and monkey eell suspensions, and the other is by H. S. Reinhold, in which he describes a combined mechanical and enzymatic method for obtaining a single cell suspension from solid tumour tissue. The method allows a concontrated suspension of a large number of cells to be prepared in a short timo. The paper from Milan by G. G. (xuidotti and others is on the inhibiting effects of aliphatic aldehydes on protein synthesis in Yoshida ascites hepatoma cells. The paper from France consists of a review by G. Mathé on immunological

* European Journal of Cancer, 1, No. 1 (June 1965). Pp. 1-74. Published quarterly. Subseription rates: $(A)$ 280s. (40 dollars) per annum for libraries, government establishmencs and research institutions; $(B) 105 s$. (15 dollars) per annum for individuals who write directly to the publisher and certify that the journal is for their personal use. (Oxford: Pergamon Press,
Jtd., 1965.) reactions in their relationship to the development of cancer and the possibility of immunotherapy in its treatment. The four remaining papers come from Belgium. R. van Nio and P. J. Thung contribute a paper on the hormonal influence of pregnancy on mouse mammary tumours and its implication for tumour behaviour and progression. J. Hildebrand and C. Coërs report six cases of polyneuritis with severe damage to peripheral nerves in patients receiving intravenous injections of $3-5 \mathrm{mg}$ vineristine per wook for varying poriods. Vineristine is an alkaloid extracted from the periwinkle flower which, although very toxic, has shown promise as an effective agent in Hodgkin's disease and certain leukaemias, and to a much lesser extent in other tumours. This study confirms previous reports of polyneuropathy caused by vincristine treatmont. Another paper dealing with a chemotherapeutic agent is that by $\mathbf{Y}$. Kenis and others, again from Brussols, which roports the results of treating patients suffering from Hodgkin's disease, various lymphomata and leukaemias, with a methylhydrazine derivative. The fourth paper, from a contre in Belgium, consists of a general review of the litorature reporting cases of metastatic liver cancer associated with renal dysplasia. This paper is contributed by G. Buyse and others from the hospital at St. Gilles and Brussels University.

The November issue contains the papers given at the International Symposium on the biological characterization of human tumours which was hold in May of last year. That these papers should have appeared in print so soon after their formal presentation show's a promptness in symposium publication which is as rare as it is commerdable.

The standard of typography and lay-out, the quality of the paper, and the illustrations are of the high standard which we have come to expect from the Pergamon Press. A particularly pleasing aspect is the way in which the bibliographical reforences are given in full with the titles of the papers quoted. This greatly increases the value of the list of references and is a house rule which could well be copied by other journal publishers. Tho annubl subseription price to individuals is a very reasonable $£ 55 s$. The annual subseription price to libraries is $£ 14$, which follows this publisher's usual practico of boing at a higher differential rate: a practice which I deplore.

D. A. Brenning 